\title{
ChILDHOOd, SchOOLING AND INCOME INEQUALITY
}

Danilo Cavapozzi, Christelle Garrouste, Omar Paccagnella 


\title{
3 Childhood, Schooling and Income Inequality
}

\author{
Danilo Cavapozzi, Christelle Garrouste, and Omar Paccagnella
}

\subsection{Childhood effects over the life-cycle}

Parental socio-economic background plays an important role in determining employment outcomes during the individual's whole life-cycle. Indeed, the environment in which individuals grow up plays a crucial role in determining their later socio-economic condition, regardless of their own abilities. On the one hand, this link might be due to the transmission of social norms (e.g. work ethics) or risk attitudes from parents to children. On the other hand, public policies may strengthen or weaken cross-generational persistence in the socio-economic status. For instance, whereas elitist education systems support the assumption of innate abilities and therefore focus their efforts and resources on the most promising pupils, redistributive policies supporting access to education at all levels (i.e. egalitarian education systems) are a typical example of interventions aimed at loosening the dependence between human capital accumulation and parental background. After the Second World War and up to the early 1980s, European education systems were demonstrating high within-country variance in learning achievement (e.g., Foshay et al., 1962). Progressively, most countries did, however, move from elitist systems to more egalitarian systems (EGREES, 2003).

Our analysis exploits the richness of the SHARELIFE data on household economic resources and cultural background of respondents at the age of 10 to address two main research questions. First, we want to show how disparities in the financial and cultural background during childhood are correlated with disparities in education and income at the first job. We focus on educational attainment and incomes at the beginning of the working career because these outcomes are more likely to take place at a stage of the life-cycle relatively close to childhood and youth and to reflect the influence of parental household status. Second, we will study the correlation between income inequality at first job and education controlling for childhood background in order to evaluate to what extent policies promoting education access and longer educational attainment can be of use to reduce income dispersions at the beginning of the working career, once childhood disparities are taken into account. Finding that further full time education is associated with lower income inequality, even for those grown up in disadvantaged households, might support the hypothesis that financing education access at all levels can be an effective strategy to lower income dispersion and finalize the pol- 
icy goal set by the European Union to decrease income disparities by the next decade (European Commission, 2010).

The paper is organized in four sections. While section 3.2 presents crosscountry heterogeneity in childhood background, the empirical correlation between childhood and respondents' socio-economic outcomes is investigated in sections 3.3 and 3.4 respectively. Finally, section 3.5 summarizes the main findings of our analysis and discusses how public policies contribute to explain cross-country differences.

\subsection{Childhood socio-economic indicators}

We take advantage of the SHARELIFE questionnaire to calculate the number of rooms per capita in the (private) accommodation where respondents lived at the age of 10. According to the questionnaire, the number of rooms considered in this analysis excludes kitchen, bathrooms and hallways, but includes bedrooms. We opt to consider rooms per capita instead of the overall number of rooms in the accommodation because this latter index is clearly affected by between and within country variability in household size, which limits its comparability. The roomsper-capita indicator circumvents this problem and is expected to be a more adequate proxy of the level of household economic resources available during respondents' childhood. Indeed, lower levels of rooms per capita suggest the presence of overcrowding in the accommodation, which is an indicator of financial distress. To this end, it is worth noting that we found a strong and positive correlation (correlation index $=0.82$ ) between our rooms-per-capita index and the OECD average disposable income of households with children aged 0-17 (OECD, 2008). This evidence supports our claim that rooms-per-capita is a sound indicator of parental financial status during childhood years.

Denmark, Belgium and Switzerland are the countries associated with the highest relative provision of rooms when the SHARELIFE respondents were ten years old. In these countries, the average number of rooms per capita is around 0.90 , i.e. each household member had almost one room at her disposal. On the contrary, Eastern Europe and Mediterranean countries present the lowest level of room provision. Noteworthy, while in Poland the number of rooms per capita is 0.39 , in the Czech Republic and Mediterranean countries it is, on average, about 0.55.

The second indicator is obtained by the SHARELIFE question that asks respondents to provide an estimate of the number of books available in their accommodation at the age of 10 . Book availability is measured in terms of number of shelves and bookcases that can be filled. Magazines, newspapers and school books are not considered. This indicator is expected to be correlated with the cultural background of the household where respondents grew up. This reasoning is confirmed by the strong and positive relationship (correlation index $=0.66$ ) existing between number of books at home and country averages for years of education in 
the adult population reported by Barro and Lee (2000). Then, the higher the number of books, the higher is the expected average educational level of parents, siblings and other relatives in the household.

The original information collected by the SHARELIFE questionnaire is rearranged to discriminate between respondents who had enough books to fill one bookcase and those having fewer books in their accommodation. On average, two thirds of respondents declare fewer books than the equivalent of one bookcase, but this overall result hides relevant cross-country variability. We notice that Mediterranean countries and Poland are by far the countries where books were less widespread in parental respondents' houses (more than 80 percent of respondents in these countries declare scarcity of books). In particular, this proportion is almost 90 percent for Italians and Greeks. On the contrary, only 40 percent of Swedes, Danes and Czechs spent their childhood in a place with few books. Notably, the pattern found for Czech Republic is at odds with that characterizing Poland. In the former country, individuals growing up in an environment with few books are less than one half than those in the latter. Among the remaining countries, respondents living in Belgium, France or Austria are those who experience the highest bookshortage during childhood.

Overall, our indicators show relevant cross-country heterogeneity in room provision and number of books in the accommodation of respondents at the age of 10 . We chose to base our study on such indicators since both of them explicitly refer to the same stage of respondents' childhood (age of 10) and the information conveyed by them can easily be compared across respondents and countries. In fact, the concepts underlying rooms per capita and number of books are objective and cannot be altered by individual reporting styles due to, for instance, cross-country heterogeneity in tradition and social norms.

The next step of our analysis is to look at the correlations between these childhood indicators and the number of years spent in full-time education by respondents. Assuming that rooms per capita and number of books are good predictors of financial status and cultural background of parental household, such analysis will help understanding whether inequalities in the resources available during childhood end up in significant differences in individuals' educational attainments.

\subsection{Childhood resources and educational attainments}

As discussed above, the number of rooms per capita is correlated with household financial status and might be of help to discriminate between better off and worse off households. To address this issue, we split respondents in two groups: in the former we group all individuals reporting a number of rooms per capita lower than the 25th percentile of their country, the latter includes those with a higher level of relative room provision. We used country-specific percentiles to allow for crosscountry heterogeneity in overall macro-economic conditions and accommodation 
arrangements. Given the positive correlation between rooms per capita and average disposable income, individuals who are at the bottom of their country ranking of rooms per capita are expected to be those living in worse off households.

Figure 3.1: Years of full time education, by country and rooms per capita at the age of 10

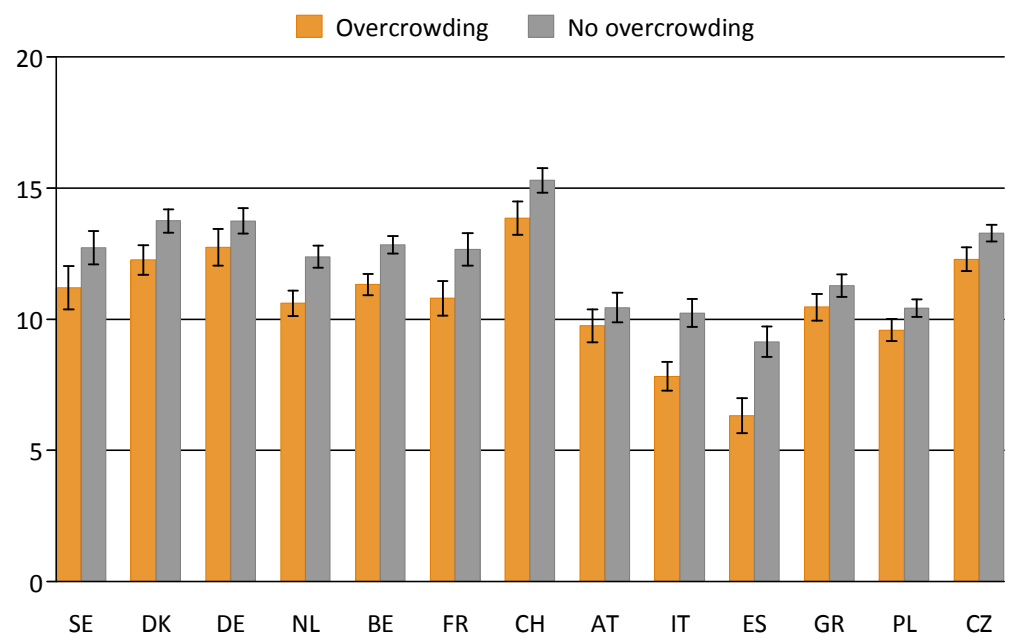

Figure 3.1 shows the average number of years spent in full time education by country and by relative level of room provision. In our analysis time spent in full time education is calculated taking into account the fact that the age when starting schooling varies over time and across countries. Moreover, it should be noted that the evidence in this section shows the relationship between childhood background and education controlling for gender and birth-cohort heterogeneity. On average, individuals with lower levels of rooms per capita spent about two years less in full time education than those who lived in an accommodation with more rooms per capita. This difference, although small on average, is statistically significant in most countries and suggests that individuals with better off parental households have spent a higher number of years in full time education. The widest differentials are found for Italy and Spain, where living in accommodations with a lower number of rooms per capita is associated with a reduction in the full time education period by more than two years.

Figure 3.2 shows the variation across countries in the average number of years spent in full time education by availability of books in respondents' accommodation. Since the number of books in the accommodation may increase with the number of household members, in addition to gender and year of birth fixed effects, we also control for household size. On average, respondents who have more 
books at their disposal remain in full time education three years longer. This variation is statistically significant.

Figure 3.2: $\quad$ Years of full time education, by country and number of books in the accommodation at the age of 10

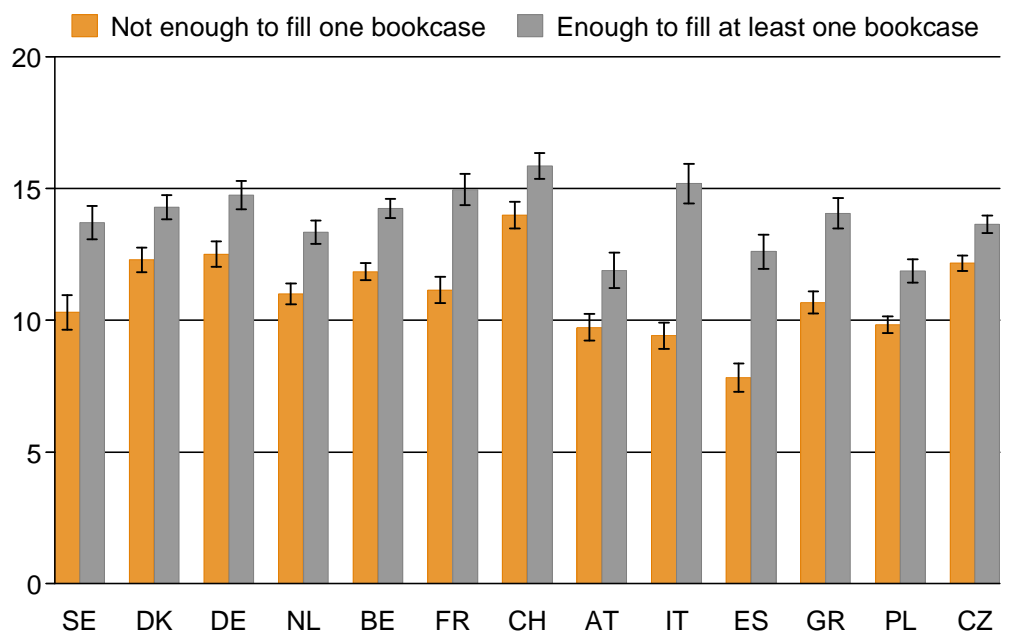

On the one hand, Denmark, Switzerland and the Czech Republic are the countries where the variation is the lowest and amount to less than two years. On the other hand, education differentials are the widest for France, Italy and Spain. In particular, for Italy it amounts to almost six years on average. Hence, cultural background affects significantly the amount of full-time education received in all countries. Better educated households are associated with a higher educational attainment. As before, the strength of this link exhibits clear cross-country variations. Again, the relationship between education outcomes and cultural background of household members appears more pervasive for Italy and Spain. The results from Figures 3.1 and 3.2 were confirmed when re-running the regression considering the variability of the control factors both by country and by group.

This evidence, overall, reconciles with what we found earlier when investigating the relationship between education and the financial status of parental household. Institutions of Italy and Spain seem to be those less able to encourage intergenerational mobility and loosen the influence of parental socio-economic background on children outcomes. These within- and between-country differences confirm the findings from the first twelve-country study of 1959-1961 by the UNESCO Institute for Education (Foshay et al., 1962). Comparing internationally standardized scores of 13-year-olds from mathematics, non-verbal, reading, geography and science tests, that pioneer study revealed a difference of roughly three-fourths of a 
standard deviation in average score between the father's lowest educational category and the highest, and a range of about two-thirds between extreme father's occupational groupings.

\subsection{Childhood resources and income inequality}

In this section we analyse how respondents' incomes are related to the socioeconomic status of their parents and how education attainment affects the reproduction of that socio-economic status. Investigating these relationships is particularly relevant in the European context as the reduction of income disparities has become one of the five headline targets for the EU27 to be reached by 2020, alongside with higher educational attainment (European Commission, 2010).

As demonstrated by the literature, the relationship between the distribution of incomes and the distribution of educational attainment is indeed twofold: first, the presence of income inequality during childhood may prevent access to education when education is too costly and may prevent equal achievement when it is combined with socio-cultural inequality; second, improved access to education is expected to raise the earning opportunities of the lower strata and, ceteris paribus, reduce earnings inequality (Mayer, 2010). Hence, policy measures easing access to education constitute a key tool against a self-perpetuating poverty trap.

In this analysis we focus on the cohort of respondents born in 1940 or later who had at least one paid job (as employee or self-employed) and report their initial income from work after taxes. It is worth noting that considering only respondents born in 1940 or later leads to exclude from the analysis about one third of the original sample but has the advantage of partially controlling for cohort effects because we consider only the individuals who grew up in the period following the World War II. Also, since we are focusing on individuals having at least one employment spell, we dropped all the respondents in this so-selected sample who have never worked in their life (about 6.5\%). For each country we consider only the amounts expressed in euro or pre-euro local currency and exclude individuals who do not report usable information on the amount and the currency of their first income from work as well as for the year in which their first employment spell started. Within-country revaluations and devaluations of local currencies have been taken into account. We use consumer price indices (base 2006) to control for time-varying inflation rates and calculate amounts in real terms. Since product price formation was centrally controlled in all countries of the Soviet bloc until the 1990s, we exclude amounts expressed in East Germany marks and individuals living in Poland and Czech Republic. Our final sample consists of about 8200 observations.

We measure income inequality by means of the interquartile range (IQR) to the median ratio (Christelis et al., 2009). Specifically, the IQR is defined as the difference between the 75 th income percentile and the 25 th income percentile. We opt 
to consider this relative measure of income inequality rather than the standard coefficient of variation (standard deviation to mean ratio) because median and interquartile ranges are more robust to outliers in the distribution tails than means and standard deviations. Outliers might produce spurious heterogeneity in income amounts due to memory effects that affect respondents' answers when they are asked to recall events occurred in the past. We point out that the IQR to the median indicator can by construction be directly compared across countries, since it overcomes the problem of the currency in which amounts are expressed.

We look at the relationship between income inequality at first job and number of books in childhood accommodations. First, we notice that median first income for respondents with scarcity of books tends to be lower than median first income for respondents with a higher number of books. Figure 3.3 shows how the IQR to median ratio indicator for the first job income varies with the availability of books in the parental accommodation. As expected, we find that countries with lower proportions of individuals grown up in households with few books are those with lower income inequality. Moreover, the gender disaggregation reveals a weaker correlation between the number of books and income inequality for women than for men and less variability of the IQR to the median. Regardless of the gender, Scandinavian countries, Switzerland, Germany and the Netherlands report both lower proportions of individuals with few books in their accommodation at the age of 10 and lower income dispersion around the median. Vice versa, Mediterranean countries report more individuals with few books at home during childhood and higher income dispersion.

Figure 3.3: Relationship between IQR to median ratio for first job incomes and number of books in the accommodation at the age of 10 by gender
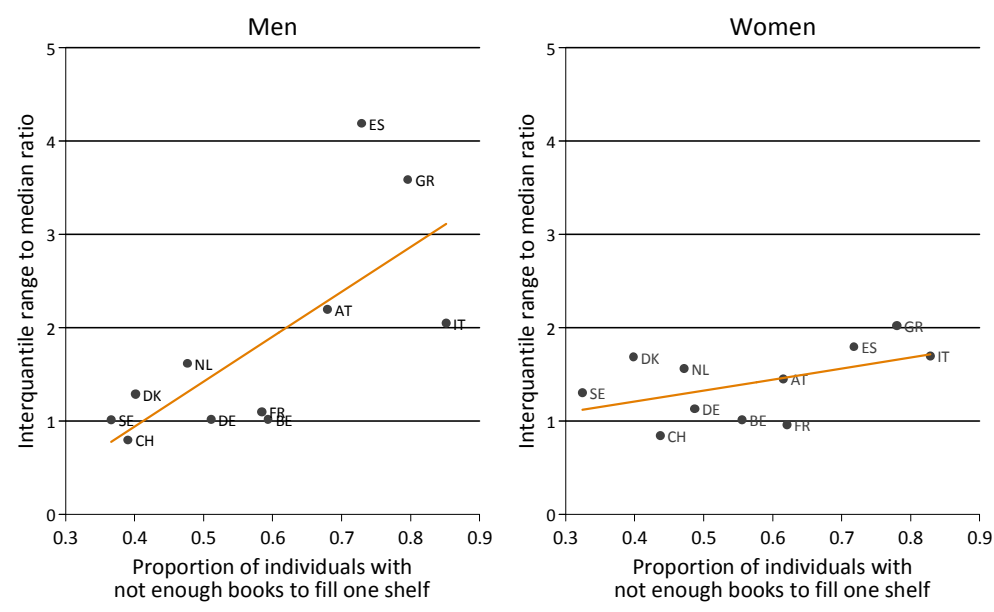
We now consider the relationship between first job incomes and number of rooms per capita in parental houses at the age of 10. As before, the median first income for respondents who lived in an overcrowded house is overall lower than the median first income for respondents who did not live in an overcrowded house. Figure 3.4 shows the variations across countries of the IQR to median ratio for the first job income by gender and rooms per capita at the age of 10. Results are comparable to those of Figure 3.3: countries where individuals grew up in accommodations with lower number of rooms per capita are those with the highest income inequality. This suggests that countries with lower disparities in the economic resources available during childhood are also those where employment and selfemployment income at the first job is more concentrated around the median. Remarkably, we noticed that the North-South gradient reported in Figure 3.3 is entirely confirmed in Figure 3.4. Further, we still find a significant difference across genders with a much stronger correlation between IQR and childhood housing conditions for men and less dispersion for women.

Figure 3.4: Relationship between IQR to median ratio for first job incomes and average rooms per capita by gender
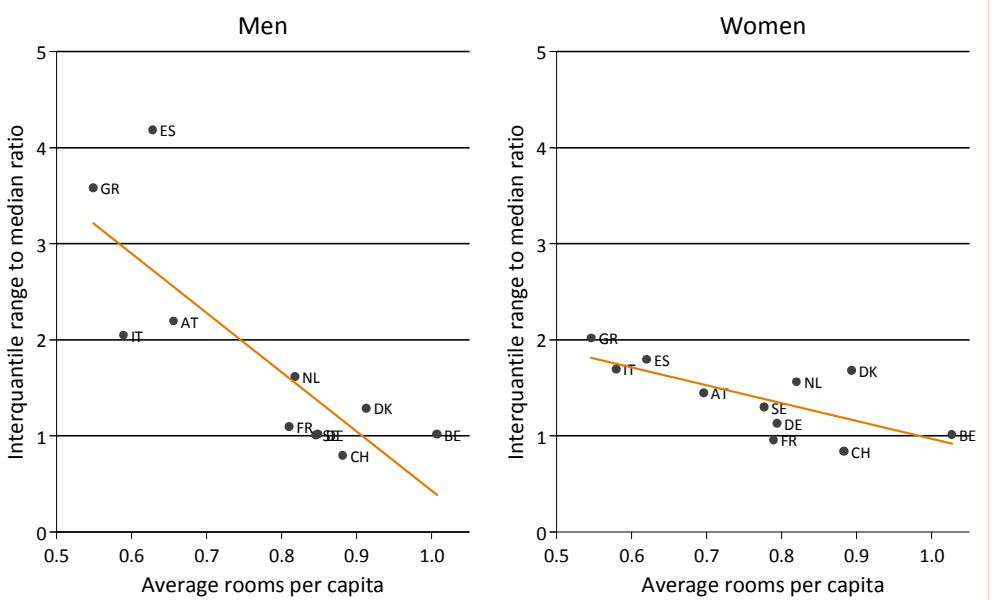

The findings presented so far in this section suggest that the childhood background is significantly correlated with income inequality at first job. Overall, countries where individuals are more likely to grow up in better-off and better-educated households always show lower income inequality. Income inequalities are, however, even more affected by the childhood factors in the case of men than in the case of women. Cross-gender differences in this relationship as well as income 
inequality levels may result from cross-gender heterogeneity in labour market participation and the relative homogeneity in the types of jobs women attended compared to men. To this end, it is worth noting that ILO statistics confirm both these arguments. They show that women at work between 1945 and 1970 constituted, on average, $26 \%$ of the total labour force and that they were mostly concentrated in services and industry sectors.

Given the relationship between childhood background and years of education (cf. Figures 3.1 and 3.2), we expect lower income inequality in countries where individuals spent on average more years in full-time education.

Figure 3.5: Relationship between IQR to median ratio for first job incomes and average years of education by gender
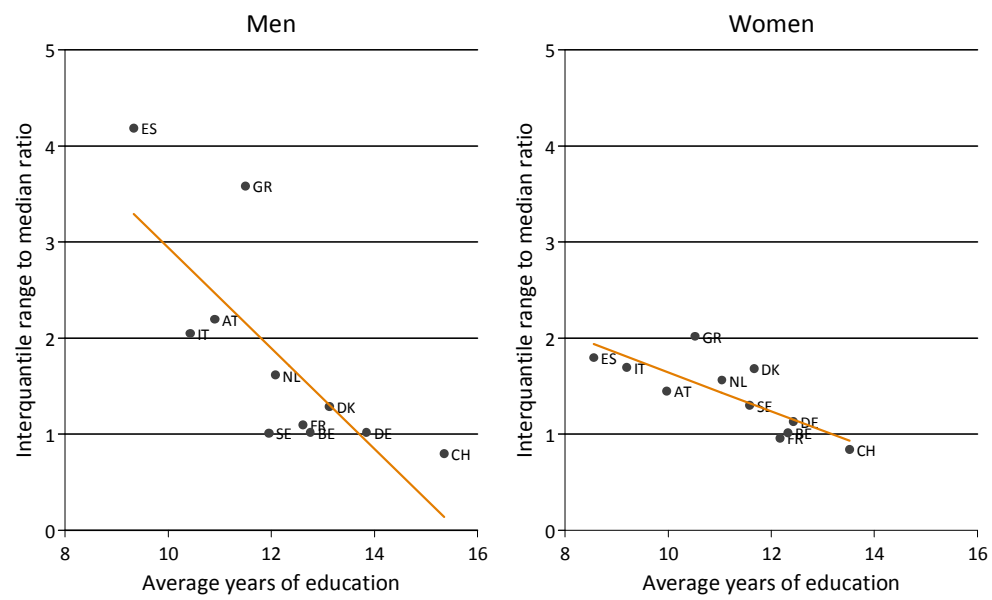

Figure 3.5 confirms this pattern. On average, the higher the number of years of education, the lower is the IQR to median ratio for first incomes, with again a lower dispersion for women than for men. Such country level information is used to calculate the percentage variations in the income dispersion at first job with respect to a marginal change in the years of education. An increase in the average time spent at school by one year is correlated with a reduction in the IQR to median ratio by $28 \%$ for males and $15 \%$ for females. Although these results confirm the negative association between education and income inequalities, they do not tell how this relationship is affected by family background. Indeed, it can be argued that countries where individuals spend on average more years in full-time education are also those where children are more likely to grow up in better educated and richer households. In other words, the positive correlation between the socio-economic condition of the parental household and educational attainments 
might drive the evidence reported in Figure 3.5 and lead to misleading interpretations on the association between education and income inequality.

Therefore, to address this issue we study the relationship between income inequality and education disaggregating the sample by gender and childhood background in terms of number of books and rooms per capita in the accommodation at the age of 10. Overall, our results show that income inequality and education are negatively related even controlling for parental household characteristics. Thus the evidence in Figure 3.5 seems not to be driven by heterogeneity in the sample composition due to childhood background disparities.

In particular, Figure 3.6 and Figure 3.7 respectively illustrate our findings for individuals from low economic background (i.e. crowded housing condition) and from low socio-cultural background (i.e. a number of books not sufficient to fill one bookcase). Regardless of the childhood indicator considered, there is a clear negative relationship between average years of education and income inequality for both men and women. Higher education is associated with lower income dispersion even if individuals grew up in socio-economically disadvantaged households. If we focus on males experiencing overcrowding or book shortage at the age of 10 , a marginal increase in the average years of education is associated with a decrease in the IQR to median ratio by $11 \%$ and $23 \%$ respectively. For females, these reductions are equal to $14 \%$ in both cases. Although these estimates do not describe causal effects, they stress the strong relationship existing between income variability and educational attainments in our sample.

Our descriptive evidence clearly suggests that public policies fostering education access and extending the length of full time educational attainment can be an effective strategy to decrease income inequalities in Europe. To provide a further underpinning to this interpretation, Figure 3.8 crosses our measure of income inequality with contextual data on public educational expenditures per pupil at primary and secondary schools from 1975 (Barro and Lee, 1997). All amounts are expressed in PPP-adjusted 1985 international dollars and make it possible to draw meaningful cross-country comparisons. Figure 3.8 shows that higher amounts of resources devoted to primary and secondary education are associated with lower income inequality at first job. Notably, in both cases Italy, Spain and Greece combine high levels of income inequality with low educational expenditures per pupil. Hence, this later result comforts our assumption that public intervention in education access may play an important role in explaining income inequalities at the beginning of the working career.

Figure 3.6: Individuals experiencing overcrowding in the accommodation at the age of 10 : relationship between IQR to median ratio for first job incomes and years of education by gender 

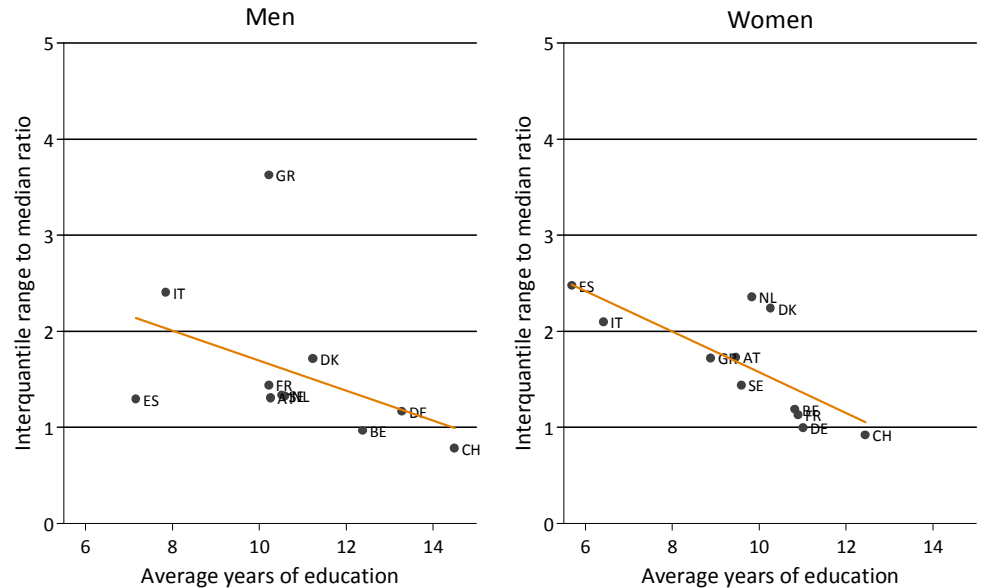

Figure 3.7: Individuals experiencing book shortage in the accommodation at the age of 10: relationship between IQR to median ratio for first job incomes and years of education by gender
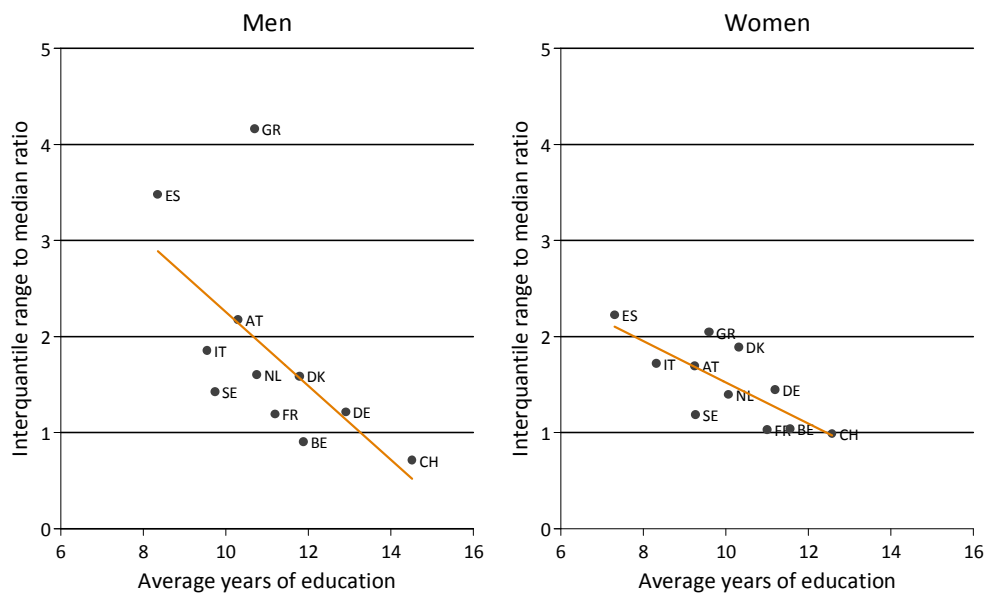

Figure 3.8: Relationship between IQR to median ratio for first job incomes and educational expenditures per pupil at primary and secondary school 

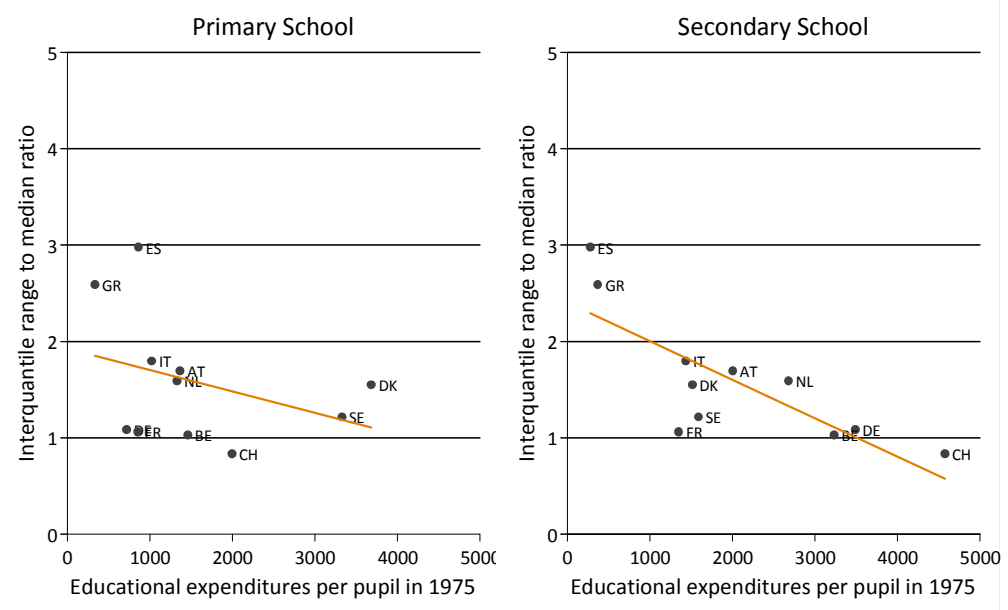

\subsection{Discussion and concluding remarks}

This contribution provides descriptive evidence that financial and educational background of parental household plays an important role in determining individual socio-economic outcomes. Educational attainments (years of schooling) and income inequality are shown to vary with the environment in which individuals grew up. In particular, respondents living in better off and better educated contexts, on average, remain in full time education longer and exhibit lower income inequality. This pattern is present in all countries and it is found to be particularly pervasive for Mediterranean countries which associate poorer socio-economic conditions during childhood with higher differentials in years of full-time education and higher income inequality.

Education policies may play a role in explaining these observed differences across countries. The introduction of support systems fostering access to education of students from disadvantaged households can weaken their financial dependence from parents and loosen the persistence in socio-economic conditions across generations (Mayer, 2010). Typical examples of these policies are government supported loans or grants to finance higher studies. OECD analyses (OECD, 2010) show that in countries where support programs are available students from worse off households have a lower gap in the probability of attaining tertiary education levels with respect to their counterparts living in high income households. Indeed, this evidence is in line with our results showing that education differentials associated with childhood background are larger in Mediterranean countries, where no universal funding systems were available at the time of schooling of our sample, 
than in Denmark, where some forms of tuitions or grants were already experimented for pupils from more disadvantaged background (Garrouste, 2010).

In addition, our analysis shows that the countries where individuals remain in full-time education longer present lower income disparities and that this negative correlation is confirmed even after controlling for childhood background. This amounts to say that, once we compare individuals growing up in similar childhood environments, we still find a negative relationship between education and income inequality at the first job. Conditioning on childhood socio-economic status reveals that this pattern is not driven by heterogeneity in the sample composition assigning individuals coming from more disadvantaged households to lower educational attainments and higher variability in their income. Thus, public policies fostering education access and increasing the number of years spent in full time education may qualify as a possible strategy to reduce income dispersions at entrance to the labour market.

\section{References}

Barro, R.J., \& Lee, J.-W., 1997. Schooling Quality in a cross Section of Countries. NBER Working Paper No. W6198, September.

Barro, R.J., \& Lee, J.-W., 2000. International data on educational attainment: updates and implications. CID Working Paper No. 042, April.

Christelis, D., Jappelli, T., Paccagnella, O., \& Weber, G., 2009. Income, wealth and financial fragility in Europe. Journal of European Social Policy, Vol. 19(4), pp. 359-376.

European Commission, 2010. Europe 2020 Plan., available at URL: http://ec.europa.eu/news/economy/100303_en.htm)

EGREES, 2003. Equity of the European educational systems: a set of indicators. Liège: Department of Theoretical and Experimental Education, University of Liège.

Foshay, A.W., Thorndike, R.L., Hotyaat, F., Pidgeon, D.A., \& Walker, D.A., 1962. Educational achievements of thirteen-year-olds in twelve countries. Hamburg: UNESCO Institute for Education, International Studies in Education.

Garrouste, C., 2010. 100 Years of educational reforms in Europe: a contextual database. Luxembourg: Publications Office of the European Union, EUR 24487 EN.

Mayer, S.E., 2010. The relationship between income inequality and inequality in schooling. Theory and Research in Education, Vol. 8(1), pp. 5-20.

OECD, 2008. Growing unequal - income distribution and poverty in OECD countries. Paris.

OECD, 2010. Economic policy reforms: going for growth. Paris: OECD Publications. 